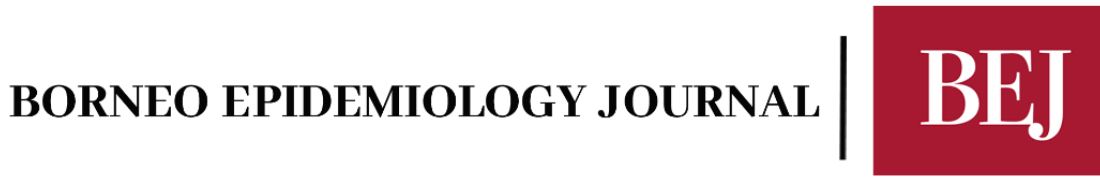

\title{
COVID-19: Need of the hour to revisit asymptomatic prevalence of coronavirus pandemic
}

\author{
Richard Avoi $^{1 *}$, Syed Sharizman Syed Abdul Rahim ${ }^{1}$, Mohammad Saffree Jeffree ${ }^{1}$ and \\ Pasupuleti Visweswara $\mathrm{Rao}^{2 * *}$ \\ Department of Community and Family Medicine, Faculty of Medicine and Health Sciences, \\ Universiti Malaysia Sabah, Kota Kinabalu, 88400, Sabah, Malaysia \\ Department of Biomedical Sciences and therapeutics, Faculty of Medicine and Health \\ Sciences, Universiti Malaysia Sabah, Kota Kinabalu, 88400, Sabah, Malaysia \\ Corresponding author:*richard.avoi@ums.edu.my; **pvrao@ums.edu.my
}

Received:28/05/2020

Accepted:09/06/2020

Since the Coronavirus disease 2019 (COVID-19) pandemic unfolded in China (Huang et al., 2020) back in December 2019, thus far, more than five million people were infected with the virus and 333,401 death were recorded worldwide (WHO, 2020b). The exponential increase in number shows that COVID-19 spreads faster compared to Severe Acute Respiratory Syndrome (SARS) or Middle East Respiratory Syndrome (MERS). A study (Zou et al., 2020) has shown that high viral loads of Severe acute respiratory syndrome coronavirus 2 (SARS-CoV-2) are detected in symptomatic patients soon after the onset of symptoms, wherein the load content is higher in their nose than in their throat. Furthermore, the same study has revealed similar viral loads between symptomatic and asymptomatic patients. Therefore, these findings may suggest the possibility of COVID-19 transmission earlier before the onset of symptoms itself. In the early stages of the pandemic, the control measures carried out have focused on screening of symptomatic person; at the time, the whole world thought that the spread of SARS-Cov-2 would only occur through symptomatic person-to-person transmission. In comparison, transmission in SARS would happen after the onset of illness, whereby the viral loads in the respiratory tract peaked around ten days after the development of symptoms by patients (Peiris et al., 2003). However, case detection for SARS (i.e. screening of symptomatic persons) will be grossly inadequate for the current COVID-19 pandemic, thus requiring different strategies to detect those infected with SARS-CoV-2 before they develop the symptoms.

With the current knowledge, the World Health Organization (WHO) describes three routes of COVID-19 transmission (WHO, 2020c) namely symptomatic, pre-symptomatic, and asymptomatic individuals infected with the virus. In particular, symptomatic transmission refers to the transmission from a person while they are experiencing the signs and symptoms compatible with COVID-19 virus infection. Meanwhile, pre-symptomatic transmission 
describes the transmission occurring from a person with a laboratory-confirmed COVID-19 infection before they develop any symptoms, wherein they will eventually display the associated symptoms accordingly. Finally, asymptomatic transmission denotes transmission of the virus from a person who does not develop symptoms throughout the entire course of illness.

Data from different countries show that people are tested positive for SARS-CoV-2 infection a few days before they develop any symptoms. Based on a study of COVID-19 clusters in Singapore, it is shown that transmission can occur 1-3 days before the source patient develops the symptoms (Wei et al., 2020). Similarly, the report (WHO, 2020a) generated by WHO-China Joint Mission on COVID-19 has yielded evidence revealing cases that are asymptomatic on the date of identification have later went on to develop symptoms. Moreover, the investigation by Zhen et al. on two clusters of COVID-19 in Zhejiang Province, China has clearly detailed the evidence of pre-symptomatic transmission could occurring among family members (Tong et al., 2020). Additionally, some studies (Lavezzo et al., 2020; Pan et al., 2020) have revealed that the COVID-19 transmission can occur from persons infected with SARS$\mathrm{CoV}-2$ who remained asymptomatic.

In general, data detailing the evidence of COVID-19 transmission from presymptomatic or asymptomatic persons with SARS-CoV-2 infection are increasing; however, those describing the actual proportion of persons with COVID-19 who are asymptomatic and pre-symptomatic are still lacking. This information is essential to estimate the total number of infections in the population through mathematical modelling. Studies showed that $17.9 \%$ of COVID-19 infections were completely asymptomatic on the Diamond Princess Cruise Ship (Mizumoto et al., 2020), while a 33.3\% rate was recorded in Japanese people who were evacuated from Wuhan (Nishiura et al., 2020).

In Malaysia, a total of 12,384 students, teachers, and staff of Madrasah Tahfiz schools were screened for SARS-CoV-2 infection using reverse transcription polymerase chain reaction (RT-PCR), wherein 635 people were found positive $(\mathrm{MOH}, 2020)$. Of this amount of confirmed cases, $539(84.5 \%)$ patients had no symptoms at diagnosis. However, no details are available on the clinical progression of the cases. Similarly, a high proportion of about $85 \%$ COVID-19 cases reported in the state of Sabah, Malaysia, was also asymptomatic at diagnosis (JKNS, 2020). These figures are alarming as this can lead to higher transmission of COVID19 infection among their respective family members, the local community, and general population. Regardless, the approach implemented by the Ministry of Health (MOH) Malaysia consisting of targeted screening for early detection, isolation for confirmed cases, and quarantine for those who have been exposed to confirmed or suspected COVID-19 cases has seemingly prevented its spread from increasing exponentially. Besides, the timely decision made by the Government of Malaysia to implement the movement control order since March 18, 2020 has also contributed significantly towards slowing down the spread of the disease.

Henceforth, the availability of rapid antibody testing for COVID-19 cases offering high sensitivity and specificity and a well-designed study to estimate the total number of infections inclusive of both pre-symptomatic and asymptomatic cases are necessary to help and restrategise the control measures. For instance, when a study reports on a large proportion of the population having already been infected with COVID-19, the ability of asymptomatic cases to 
spread the disease will be limited and thus allowing physical distancing to be lifted. If it shows otherwise, then the practices of good personal hygiene, avoiding crowded places and mass gatherings, and social distancing should be continued. Additionally, more widespread testing for COVID-19 should be considered on top of highly effective contact tracing strategies.

Therefore, it is important to further explore the impact of asymptomatic and presymptomatic transmission on the control measures of COVID-19 infection as the current data is still inadequate.

\section{References}

Huang, C., Wang, Y., Li, X., Ren, L., Zhao, J., Hu, Y., Zhang, L., Fan, G., Xu, J., Gu, X., Cheng, Z., Yu, T., Xia, J., Wei, Y., Wu, W., Xie, X., Yin, W., Li, H., Liu, M., .. Cao, B. (2020). Clinical features of patients infected with 2019 novel coronavirus in Wuhan, China. The Lancet, 395(10223), 497-506. https://doi.org/10.1016/S0140-6736(20)30183-5

JKNS. (2020). Sabah State Health Director Press statement 20 Apr 2020. https://www.facebook.com/photo?fbid=3204624609550821\&set=pcb.3204633416216607

Lavezzo, E., Franchin, E., \& Ciavarella, C. (2020). Suppression of COVID-19 outbreak in the municipality of Vo', Italy. MedRxiv Preprint, April 18. https://www.medrxiv.org/content/10.1101/2020.04.17.20053157v1.full.pdf

Mizumoto, K., Kagaya, K., Zarebski, A., \& Chowell, G. (2020). Estimating the asymptomatic proportion of coronavirus disease 2019 (COVID-19) cases on board the Diamond Princess cruise ship, Yokohama, Japan, 2020. Eurosurveillance, 25(10), 1-5. https://doi.org/10.2807/15607917.ES.2020.25.10.2000180

MOH, M. (2020). Malaysia DG of Health Press Statement 14 May 2020. http://covid19.moh.gov.my/terkini/052020/situasi-terkini-14-mei-2020/Kenyataan Akhbar KPK COVID-19 (14 Mei 2020) - EN.pdf

Nishiura, H., Kobayashi, T., Miyama, T., Suzuki, A., Jung, S., Hayashi, K., Kinoshita, R., Yang, Y., Yuan, B., Akhmetzhanov, A. R., \& Linton, N. M. (2020). Estimation of the asymptomatic ratio of novel coronavirus infections (COVID-19). International Journal of Infectious Diseases, 94, 154155. https://doi.org/10.1016/j.ijid.2020.03.020

Pan, X., Chen, D., Xia, Y., Wu, X., Li, T., Ou, X., Zhou, L., \& Liu, J. (2020). Asymptomatic cases in a family cluster with SARS-CoV-2 infection. The Lancet Infectious Diseases, 20(4), 410-411. https://doi.org/10.1016/S1473-3099(20)30114-6

Peiris, J., Chu, C., Cheng, V., Chan, K., Hung, I., Poon, L., Law, K., Tang, B., Hon, T., Chan, C., Chan, K., Ng, J., Zheng, B., Ng, W., Lai, R., Guan, Y., \& Yuen, K. (2003). Clinical progression and viral load in a community outbreak of coronavirus-associated SARS pneumonia: a prospective study. The Lancet, 361(9371), 1767-1772. https://doi.org/10.1016/S0140-6736(03)13412-5

Tong, Z.-D., Tang, A., Li, K.-F., Li, P., Wang, H.-L., Yi, J.-P., Zhang, Y.-L., \& Yan, J.-B. (2020). Potential Presymptomatic Transmission of SARS-CoV-2, Zhejiang Province, China, 2020. Emerging Infectious Diseases, 26(5), 1052-1054. https://doi.org/10.3201/eid2605.200198

Wei, W. E., Li, Z., Chiew, C. J., Yong, S. E., Toh, M. P., \& Lee, V. J. (2020). Presymptomatic Transmission of SARS-CoV-2 - Singapore, January 23-March 16, 2020. MMWR. Morbidity and Mortality Weekly Report, 69(14), 411-415. https://doi.org/10.15585/mmwr.mm6914e1

WHO. (2020a). Report of the WHO-China Joint Mission on Coronavirus Disease 2019 (COVID-19). https://www.who.int/docs/default-source/coronaviruse/who-china-joint-mission-on-covid-19final-report.pdf

WHO. (2020b). WHO COVID-19 Situational Report-124. In World Health Organization. https://www.who.int/docs/default-source/coronaviruse/situation-reports/20200523-covid-19sitrep-124.pdf?sfvrsn=9626d639_2 
WHO. (2020c, April). WHO COVID-19 Situational Report 73, 2 April 2020. WHO. https://www.who.int/docs/default-source/coronaviruse/situation-reports/20200402-sitrep-73covid-19.pdf?sfvrsn=5ae25bc7_6

Zou, L., Ruan, F., Huang, M., Liang, L., Huang, H., Hong, Z., Yu, J., Kang, M., Song, Y., Xia, J., Guo, Q., Song, T., He, J., Yen, H.-L., Peiris, M., \& Wu, J. (2020). SARS-CoV-2 Viral Load in Upper Respiratory Specimens of Infected Patients. New England Journal of Medicine, 382(12), 11771179. https://doi.org/10.1056/NEJMc200173Huang, C., Wang, Y., Li, X., Ren, L., Zhao, J., Hu, Y., Zhang, L., Fan, G., Xu, J., Gu, X., Cheng, Z., Yu, T., Xia, J., Wei, Y., Wu, W., Xie, X., Yin, W., Li, H., Liu, M., ... Cao, B. (2020). Clinical features of patients infected with 2019 novel coronavirus in Wuhan, China. The Lancet, 395(10223), 497-506. https://doi.org/10.1016/S01406736(20)30183-5 